\title{
A District Sanitary Disposal Plant
}

\section{A Model Collection and Disposal System for City Waste Material}

\section{By Flora Spiegelburg}

In order to make the Model District a real model of sanitation and economy, it should not only include the latest perfected disposal system by means of incineration, but the mixed collection of ashes and garbage. It should also eliminate the fly and disease breeding dumps (covered ones as well as the uncovered), scows, and the pier for the collection of dead animals and condemned food.

It is now a generally accepted fact by all progressive sanitarians that a mixed collection is dustless, odorless and flyless on account of the disinfecting qualities contained in the ashes: It will, therefore, prove the most effective means of cleaning up the congested districts: by eliminating the $f y$, roaches. rats and mice, the spread of all contagious diseases will be greatly lessened.

According to an expert there are a million germs on a fly's head; surely this is the strongest plea for a mixed

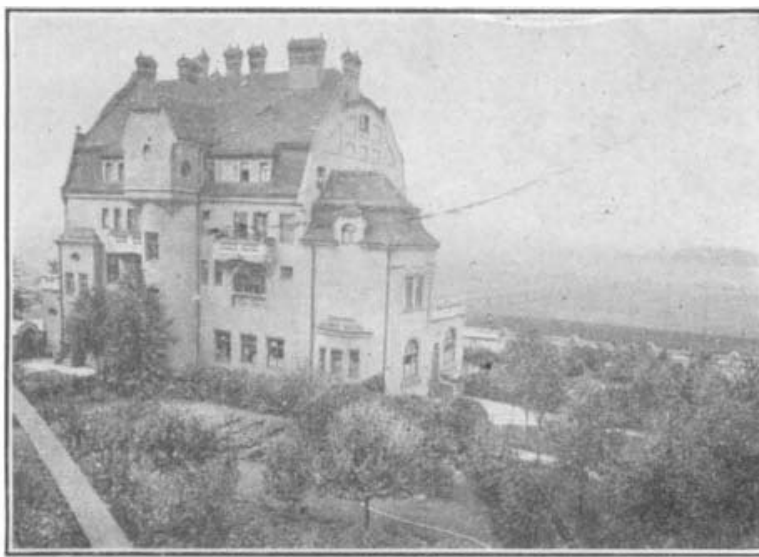

Administration building of the incinerating plan at Fuerth, Bavaria, surrounded by flower, fruit and vegetable gardens.

collection-the elimination of fly and disease breeding dumps of all kinds and the incincration of all burnable wastes, in order to have a spotless, Hyless eity.

Judging from the report of the Model District, it Judging from the report of the Model District, it
provides only for a refuse collection method. Operation and maintenance necessary for this collection as well as the many street cleaning activities, will doubtless cost the city a large sum of money.

In most European cities, in Germany and Holland in particular, the "Zone Incinerator Plant System" has for years proven suceessful and self-supporting. In Rotterdam, after running the plant, crushing the slag, etc., the excess power is used to supply the entire electric car system of the city and there is still sufficient power for the proposed motor trucks. The power power for the propor generated here would prove so even in a much greater degree. because the American garbage contains much more grease, and the ashes 20 to 30 per cent more heat ing quality, and the entire output is three to four time as large as in any European eity.

On account of the low percentage of beating qualities in the mixed collection of ashes and garbage at Frankfort-am-Main, it was found necessary to erect the incinerator on the same grounds with the sewage disposal plant, and in order to make it self-supporting the oils and grease obtained from the sewage had to be burned with the refuse.

Here, besides ashes and garbage to be used as fuel there is a large amount of condemned food, dead animals there is a large amount of condemned food, dead animals from all the departments, infected bedding, carpets, from all the departments, infected bedding, carpets, manure, street sweepings, a great quantity of broken
boxes, barrels, furniture, small burnable trade wastes boxes, barrels, furniture, small burnable trade
and an amount of rubbish which is very great. and an amount of rubbish which is very great.
The power that could be generated from this vast amount of fuel could be used to light, heat and run the entire zone plant, crush the slag or residue and run th waste disposal plant. The excess power should be turned into electric storage batteries for the use of all the various motor cars and trucks for the disposal plant, as well as all required by the Department of Street Cleaning. With the exeption of the three summer months there With the exception of the three summer months there should be still suffeient power to supply the storage batteries for many of the municipally-owned cars and trucks of the fire and health de
situated in that particular zone.

A second source of revenue, which if economically
A sed in that particular zone. A second source of revenue, which if economically
managed should be very large, is the vast amoun managed should be very large, is the vast amount
of slag or residue derived from the incinerated refuse, to be sold either for concreting purposes, road making or * Cuts by courtesy of Real Estale Bulletin. made into bricks for sewer lining or paving. This vast amount of material for building or road making purpose could also be called for daily by boat, or used in that particular zone, thus cheapening cost of haulage.

The vast amount of waste materials, such as paper, rags, tin cans, scrap iron and other metals, scrap leather, rubber and other trade wastes, should be baled. The 5 to 25 cents), bottles (milk at 1 cent) should be sold by yearly contracts to the highest bidder. In order to avoid accumulations and keep the zone spotless and flyless, much as possible by boat, thus lessening expense of haulage. As the disposal plant faces the river, it will doubtless prove not only the cheapest way but avoid mach congestion in the streets, just as the congestion and haulage of all the refuse, dead animals, condemned food and all other waste materials enumerated above will be greatly lessened by bringing everything in that particular radius to the "Zone" to be finally disposed of besides freeing our beautiful river-front from many fly and rat-ridden pest holes.

A few examples of highest efficiency in sanitation, which eliminates the flies, rodents, dumps, scows, piers for dead animals and condemned food: I personally witnessed the collection of refuse twice last summer in witnessed the collection of refuse twice last summer in
Fuerth-acknowledged to be the most perfect system in Europe. There the Ochsner system of covered receptacles and motor trucks has been successfully adopted It is absolutely dust, odor and fly proof because neithe receptacle nor wagon is uncovered during the process of collection and on arrival at the destructor a travelin crane transports a division of the motor truck directly to the oven, the bottom is opened and the refuse drops into the oven of the incinerator.

According to the proposed "Zone Plan," if two men with the motor truck started to collect ashes and garbage at seven o'clock, before eight o'clock they would be able to deposit their load at the destructor and fif teen minutes to deposit their load at the destructor and fif teen minutes later the incinerated refuse--now slag or residue--should
be cooling in the yard, opposite the destructor, before nine o'clock, ready for the crushing process, thus taking less than two hours' time for the final disposition of the refuse.

At present, in accordance with the rules of the Health Department, the scows may not remain longer than twenty-four hours loading at the dump, but it of ten happens that if not filled, the scow is detained more than two days; consequently in warm weather the stench is insupportable. Meanwhile millions of flies breed and feed (besides numberless rodents) on the decaying garbage, condemned food, diseased animals and germ laden waste materials.

But in comparison to our present unsanitary method of collecting and disposing of dead animals and condemned food the Zone Plan offers the highest, greatest and most desirable efficiency, namely, if a horse drops dead of glanders, or spoiled food has been condemned, the Health Department 'phones to the Inspector of the Zone Plant; he immediately sends his animal truck or should it be on duty, it cannot be away more than hal an hour within the radius of the Zone. So now again an hour within the radius of the Zone. So now again than one hour after the dead horse or any other animal, or condemned food, has been incinerated and is cool ing in a sanitary, fly less, odorless state, ready like the other refuse to be added to the slag and made into bricks for paving or other purposes. All infected bedding an clothing can be disposed of just as quickly and cheaply. In conclusion I venture to predict that possibly sufficient revenue may be obtained from the power generated, the sale of the slap and various waste materials to make the in the the incinorator more than self-supporting. Add to this numberless other expenses at present. Also consider the revenue diverted to the city from the use of the piers $(\$ 10,000$ from each borough) for the disposal of dead animals and condemned food.

Naturally, according to the vast amount and quality of refuse and waste materials collected in each Zone, it must differ correspondingly in its amount of revenue, but

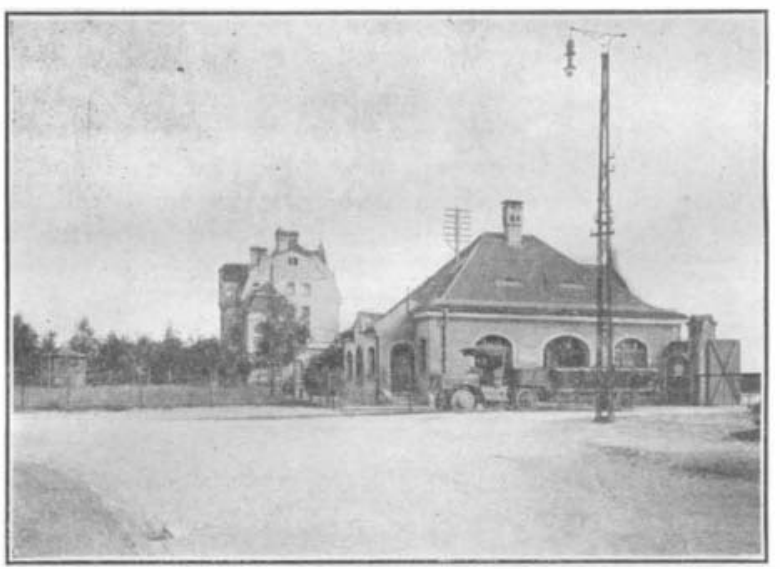

Weighing motor refuse wagon at entrance to incinerating plant.

since it will go directly into the treasury of the Department of Street Cleaning, it will certainly solve the muchto-be-desired problem of helping to place the department on a self-maintaining basis, or in other words, cut down the present expenses as much as possible.

But in order not to be misunderstood in offering this carefully laid out plan which includes every modern improvement for the collection and disposal of all eity waste materials, the administration thereof, as well as sanitary working facilities for all laboring men at the Zone and the entire street cleaning force of that particulor and the entre streot cleaning for pre zanitary and profitable Zone incinerator plant; this should be intrict, adapted to its requirements so that it might prove a real model, for the disposal system is the root of the evil and should, therefore, be considered before the collection method on account of greater sanitation.

To further perfect the sanitary regulations of the Model District, besides the dustless, odorless and flyles mixed collection and metal-covered motor trucks, the receptacles for the street sweepings should have the same non-detachable covers as those for the refuse. All waste materials should be covered; each house should baste materials should be covered; each house should be provided with a shelter or place to keep
keep refuse cans off the sidewalks.

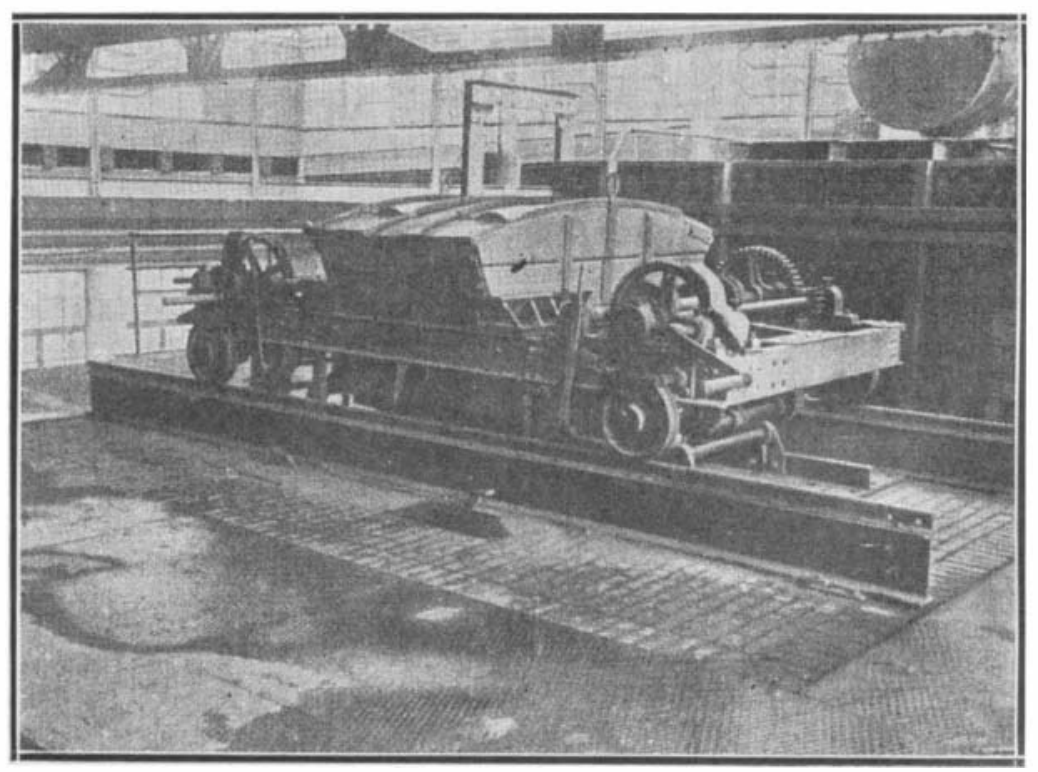

Section of motor truck body over oven of destructor, ready to be emptied into the incinerator. 